\title{
Comparison of the efficacy of glibenclamide and glimepiride in reperfusion-induced arrhythmias in rats
}

\author{
Nasruddin E. El-Reyani, Ömer Bozdogan, István Baczkó, István Leprán *, Julius Gy. Papp \\ Department of Pharmacology and Pharmacotherapy, Albert Szent-Györgyi Medical University, H-6701 Szeged, P.O. Box 115, Hungary
}

Received 17 September 1998; revised 13 November 1998; accepted 20 November 1998

\begin{abstract}
The effect of glibenclamide and glimepiride, two orally active antidiabetic sulphonylurea derivatives, was investigated on the development of reperfusion-induced arrhythmias and it was compared to their blood glucose lowering action. Arrhythmias were produced by reperfusion following 6 min coronary artery ligation in anaesthetised rats. Glimepiride pretreatment $(0.001-0.01-0.1-5.0 \mathrm{mg} / \mathrm{kg}$ i.p., $30 \mathrm{~min}$ before coronary occlusion) significantly decreased the incidence of irreversible ventricular fibrillation and increased the survival rate during reperfusion $(64 \%, 61 \%, 60 \%$, and $67 \%$ vs. $27 \%$ in controls). Glibenclamide produced similar effect ( $81 \%$ survival) only in a dose of $5 \mathrm{mg} / \mathrm{kg}$, while smaller doses were ineffective. The minimal hypoglycaemic dose and the dose required to inhibit significantly the oral glucose loading-induced hyperglycaemia were similar ( 1 and $0.1 \mathrm{mg} / \mathrm{kg}$, respectively) after glibenclamide and glimepiride. It is concluded that although the blood glucose lowering potency of glibenclamide and glimepiride is rather similar, glimepiride appears to be more potent than glibenclamide in preventing reperfusion-induced cardiac arrhythmias. C) 1999 Elsevier Science B.V. All rights reserved.
\end{abstract}

Keywords: Reperfusion arrhythmia; Glibenclamide; Glimepiride; (Rat, anaesthetized)

\section{Introduction}

ATP-dependent $\mathrm{K}^{+}$channels $\left(\mathrm{K}_{\text {АTP }}\right)$ were first described by Noma (1983) and have been found to be widely distributed particularly in pancreatic $\beta$-cells, myocardium, skeletal muscle, vascular smooth muscle cells and in neurones. In cardiac cells they may play a special role because of their high density at the cell surface, their large ion conductance and their dependence upon cell metabolism. Under normoxic conditions when ATP is available, these channels are in a closed state. However, during ischaemia, the decrease in cytosolic ATP concentration and the accumulation of ischaemic metabolites together results in opening of $\mathrm{K}_{\text {ATP }}$ channels. Several investigations have suggested that the activation of these channels during myocardial ischaemia provides a 'natural' protective effect (Escande and Cavero, 1992; Grover, 1994) via increasing the rate of repolarisation, thereby decreasing voltage dependent calcium influx to the myocardium and preserving ATP during ischaemia. On the other hand, opening of $\mathrm{K}_{\text {ATP }}$ channels during the acute phase of myocardial in-

\footnotetext{
" Corresponding author. Tel.: + 36-62-455-676; Fax: +36-62-454-565; E-mail: lepran@phcol.szote.u-szeged.hu
}

farction may contribute to the development of re-entrant type arrhythmias and sudden cardiac death.

In isolated perfused hearts during regional ischaemia and/or reperfusion glibenclamide, a $\mathrm{K}_{\mathrm{ATP}}$-channel blocker, was found to be antiarrhythmic (Wolleben et al., 1989; Kantor et al., 1990; Tosaki et al., 1993; D'Alonzo et al., 1994), and increased the chance for spontaneous recovery from ventricular fibrillation (Bril et al., 1992; Rees and Curtis, 1995). There are also some in vivo investigations showing that glibenclamide may possess antiarrhythmic activity (Ballagi-Pordany et al., 1990; Bekheit et al., 1990; Billman et al., 1993; Kondo et al., 1996). However, contrary results have also been presented. For example, glibenclamide had no effect on the incidence of ventricular fibrillation developing in response to a secondary insult in anaesthetized dogs with recent myocardial infarction (Chi et al., 1989), or in vitro against reperfusion-induced arrhythmias (Cole et al., 1991; Bernauer, 1997). Previously, we demonstrated in in vivo conditions that glibenclamide pretreatment increased the survival rate and decreased the incidence of life-threatening arrhythmias during acute myocardial infarction in conscious rats (Leprán et al., 1996) or during ischaemia/reperfusion in anaesthetised rats (Baczkó et al., 1997a). 
Structurally different sulphonylureas may have a different action against arrhythmias during myocardial ischaemia. It has been demonstrated by Ballagi-Pordany et al. (1990) that first-generation antidiabetic sulphonylureas may exacerbate arrhythmias, while second-generation compounds produce antiarrhythmic action both in experimental animals and in diabetic patients. The discovery of the heterogeneity of sulphonylurea receptors, as part of $\mathrm{K}_{\text {ATP }}$ channels (Aguilar-Bryan et al., 1998), further emphasizes the need to compare the pancreatic and extrapancreatic effects of different agents.

Glimepiride is an orally active sulphonylurea derivative, which is considered to be a more potent antidiabetic when compared to glibenclamide (Geisen, 1988; Langtry and Balfour, 1998), while producing less adverse effects in the cardiovascular system (Geisen et al., 1996). The aim of the present investigations was to compare the efficacy of glibenclamide and glimepiride in coronary artery occlusion-reperfusion-induced arrhythmias in rats and to examine whether there is a correlation between this effect and the hypoglycaemic action of these two $K_{\text {ATP }}$ channel inhibitory drugs.

\section{Materials and methods}

\subsection{Animals}

Male Sprague-Dawley rats, weighing 300-350 g were used. Animals were fed a standard laboratory rat food pellet (Altromin, Gödöllö, Hungary) and allowed to drink tap water ad libitum. The animals were handled according to a protocol reviewed and approved by the Ethical Committee for the Protection of Animals in Research of the Albert Szent-Györgyi Medical University (Szeged, Hungary).

\subsection{Blood glucose determination}

In conscious rats, a single drop of blood was taken by cutting the tip of the tail. Blood glucose concentration was measured using a med-strip test (One Touch II, Lifescan, Johnson \& Johnson, USA). A series of blood samples were taken before treatment, $30 \mathrm{~min}$ after intraperitoneal drug treatment and $30 \mathrm{~min}$ after oral administration of $1 \mathrm{~g} / \mathrm{kg}$ glucose in $5 \mathrm{ml} / \mathrm{kg}$ tap water.

\subsection{Coronary artery ligation and reperfusion}

Coronary artery ligation and reperfusion was performed as described earlier (Baczkó et al., 1997b). Animals were anaesthetised with pentobarbitone $(60 \mathrm{mg} / \mathrm{kg}$ i.p. in a volume of $2 \mathrm{ml} / \mathrm{kg}$ ). The left carotid artery was cannulated for measuring the blood pressure using a pressure transducer (Gould-Statham P23ID, Hugo Sachs Elektronik, March-Hugstetten, Germany) and was recorded on an os- cillographic recorder (Watanabe, WTR 331, Hugo Sachs Elektronik). The catheter was filled with saline that contained heparin $(500 \mathrm{IU} / \mathrm{ml})$, but the animal was not heparinized. The trachea was cannulated for artificial respiration. The chest was opened in the fourth intercostal space, the heart was exposed and a loose loop of atraumatic silk (Ethibond 5/0, Ethicon, UK) was placed around the left main coronary artery, approximately $2 \mathrm{~mm}$ from its origin. Both ends of the ligature were led out of the thoracic cavity through a flexible tubing. The heart was set back in its place and artificial respiration was started using 60 strokes /min (Harvard rodent ventilator, Model 683, Harvard Apparatus, South Natick, MA, USA). The standard electrocardiogram (lead II, ECG) was recorded using subcutaneous needle electrodes. After finishing the preparation, the animals were allowed to stabilize for $10 \mathrm{~min}$, then the loose loop of the coronary artery ligature was tightened and fixed by clamping on the silk and thus regional myocardial ischaemia was produced for $6 \mathrm{~min}$ and then followed by reperfusion for $5 \mathrm{~min}$.

Incidence of arrhythmias was analysed in accordance with the Lambeth Conventions (Walker et al., 1988), i.e., as ventricular fibrillation, ventricular tachycardia and other types of arrhythmias, including single extrasystoles, bigeminy and salvos. In case of ventricular fibrillation development, no attempt was made to defibrillate the animals.

At the termination of the experiment, heparin (500 $\mathrm{IU} / \mathrm{kg}$ ) was given intravenously and the heart was excised. The left coronary artery was re-tightened and the heart was first perfused retrogradely with $10 \mathrm{ml}$ isotonic $\mathrm{NaCl}$ solution then with $2 \mathrm{ml}$ ethanol, for the demarcation of the occluded and the non-occluded myocardium (Leprán et al., 1983). The non-perfusable area, that remained red coloured, was cut along the epicardially visible border zone and its weight was measured and expressed in percentage of the wet weight of the ventricles. Hearts showing no arrhythmias during coronary artery ligation or reperfusion and exhibiting $<10 \%$ non-perfusable area were excluded from the final evaluation. Using these criteria altogether eight animals were excluded from the experiments.

\subsection{Drug administration protocol}

Glibenclamide (Sigma-Aldrich, Hungary) or glimepiride (Hoechst, Germany) was dissolved in dimethyl sulfoxide: isotonic saline 1:1 mixture and was applied intraperitoneally $30 \mathrm{~min}$ prior to coronary artery ligation. To reduce the solvent effect, the volume of the injection was 100 $\mu \mathrm{l} / \mathrm{kg}$. Control animals were given the same volume of the solvent.

\subsection{Statistical evaluation}

The percentage incidence of arrhythmias was calculated and compared using the $\chi^{2}$-method. All other parameters 
Table 1

Effect of glibenclamide and glimepiride on the blood glucose level $(\mathrm{mmol} / \mathrm{l})$ after oral glucose loading in rats

\begin{tabular}{llll}
\hline Group & $\begin{array}{l}\text { Dose } \\
(\mathrm{mg} / \mathrm{kg})\end{array}$ & Basal & $\begin{array}{l}\text { Glucose } \\
\text { loading }\end{array}$ \\
\hline Control & & $3.2 \pm 0.16$ & $5.4 \pm 0.26$ \\
Glibenclamide & 0.01 & $3.2 \pm 0.11$ & $5.7 \pm 0.17$ \\
& 0.1 & $3.0 \pm 0.15$ & $4.4 \pm 0.21^{\mathrm{a}}$ \\
Glimepiride & 1.0 & $3.3 \pm 0.08$ & $3.4 \pm 0.18^{\mathrm{a}}$ \\
& 0.01 & $3.1 \pm 0.16$ & $5.9 \pm 0.18$ \\
& 0.1 & $3.2 \pm 0.04$ & $4.0 \pm 0.11^{\mathrm{a}}$ \\
& 1.0 & $3.5 \pm 0.06$ & $3.8 \pm 0.19^{\mathrm{a}}$ \\
\hline
\end{tabular}

Results are mean \pm S.E. of six animals in each group.

Blood glucose concentration was measured before treatment (Basal) and $30 \mathrm{~min}$ after oral administration of $1 \mathrm{~g} / \mathrm{kg}$ glucose (Glucose loading).

${ }^{a} P<0.05$ compared to the corresponding control value.

were expressed as mean \pm standard error of the mean (S.E.) and, after analysis of variance (ANOVA with repeated measures for the blood pressure and heart rate values), were compared by the modified $t$-statistic (Wallenstein et al., 1980).

\section{Results}

\subsection{Blood glucose level}

During basal conditions, i.e., before any drug treatment, the blood glucose level in conscious rats was not significantly different among different groups (Table 1). Thirty minutes after the intraperitoneal administration, both glibenclamide and glimepiride significantly reduced the blood glucose concentration when applied in a dose of 1 $\mathrm{mg} / \mathrm{kg}(2.6 \pm 0.12$ and $2.7 \pm 0.11 \mathrm{mmol} / \mathrm{l}$ in the glibenclamide and glimepiride treated animals, vs. $3.3 \pm 0.08$ and $3.5 \pm 0.06 \mathrm{mmol} / 1$ before treatment, respectively, $P$ $<0.05$ ). Both compounds already in a dose of $0.1 \mathrm{mg} / \mathrm{kg}$ inhibited the elevation of plasma glucose concentration after oral glucose loading, while the smallest dose applied $(0.01 \mathrm{mg} / \mathrm{kg})$ was without effect (Table 1).

\subsection{Haemodynamic parameters}

At the doses that did not influence the blood glucose concentration in conscious rats, neither glibenclamide nor glimepiride pretreatment influenced significantly the heart rate or blood pressure as measured before coronary artery ligation in anaesthetised rats (Table 2). These haemodynamic parameters did not differ from the control during coronary artery ligation. Large doses of either glibenclamide or glimepiride (i.e., $5 \mathrm{mg} / \mathrm{kg}$ i.p.), however, significantly increased the heart rate before coronary artery ligation and this remained high also during the experiment after glimepiride pretreatment (Table 2). It was difficult to measure the heart rate or blood pressure during reperfusion, due to frequent arrhythmias in this period. When it was possible to perform statistical analysis, no significant differences were observed after glibenclamide or glimepiride pretreatment as compared to the control group.

\subsection{Arrhythmias during coronary artery ligation}

In the present experiments, coronary artery ligation lasting for $6 \mathrm{~min}$ was not enough to develop severe, ischaemia-induced arrhythmias. There were no significant differences among different treatments concerning the incidence of arrhythmias or the survival rate during coronary ligation.

\subsection{Arrhythmias during reperfusion}

Arrhythmias induced by reperfusion after 6 min myocardial ischaemia started within $10-30 \mathrm{~s}$ following the release of the coronary artery ligature. Irreversible ventric-

Table 2

Effect of glibenclamide and glimepiride on the heart rate (HR) and mean arterial blood pressure (BP) in anaesthetised rats

\begin{tabular}{|c|c|c|c|c|c|c|c|c|c|c|}
\hline \multirow[t]{2}{*}{ Group } & \multirow{2}{*}{$\begin{array}{l}\text { Dose } \\
(\mathrm{mg} / \mathrm{kg})\end{array}$} & \multicolumn{3}{|c|}{$\underline{\text { Basal }}$} & \multicolumn{3}{|c|}{ Occlusion } & \multicolumn{3}{|c|}{ Reperfusion } \\
\hline & & n1 & HR & BP & $\mathrm{n} 2$ & HR & BP & n3 & HR & BP \\
\hline Control & & 26 & $389 \pm 7.5$ & $110 \pm 3.8$ & 22 & $374 \pm 8.5$ & $80 \pm 7.2$ & 6 & $450 \pm 27.6$ & $86 \pm 14.7$ \\
\hline \multirow[t]{2}{*}{ Glibenclamide } & 0.01 & 16 & $379 \pm 9.1$ & $105 \pm 5.1$ & 13 & $364 \pm 9.4$ & $73 \pm 5.6$ & 4 & ND & ND \\
\hline & 5.0 & 20 & $432 \pm 7.5^{\mathrm{a}}$ & $104 \pm 5.5$ & 16 & $398 \pm 15.3$ & $49 \pm 4.8^{\mathrm{a}}$ & 13 & $432 \pm 11.6$ & $89 \pm 9.6$ \\
\hline \multirow[t]{3}{*}{ Glimepiride } & 0.0001 & 9 & $337 \pm 9.0$ & $121 \pm 6.7$ & 8 & $312 \pm 10.9$ & $72 \pm 11.7$ & 3 & ND & ND \\
\hline & 0.001 & 23 & $384 \pm 12.4$ & $109 \pm 3.6$ & 22 & $369 \pm 15.1$ & $78 \pm 7.8$ & 14 & $398 \pm 23.5$ & $92 \pm 8.4$ \\
\hline & 5.0 & 22 & $428 \pm 7.7^{\mathrm{a}}$ & $108 \pm 4.6$ & 18 & $415 \pm 9.8^{\mathrm{a}}$ & $87 \pm 5.5$ & 12 & $429 \pm 13.2$ & $102 \pm 7.5$ \\
\hline
\end{tabular}

Results are mean \pm S.E. of the animals surviving the given period ( $\mathrm{n} 1, \mathrm{n} 2$ and $\mathrm{n} 3$ means the number of these animals, respectively).

Heart rate (HR) and mean arterial blood pressure was measured before coronary artery ligation (Basal), 5 min after coronary ligation (Occlusion) and 5 min after the release of occlusion (Reperfusion). $\mathrm{ND}=$ Not determined because of few surviving animals.

${ }^{\text {a }} P<0.05$ compared to the corresponding control value. 
Table 3

Effect of glibenclamide and glimepiride on the incidence of arrhythmias during reperfusion after 6 min coronary artery ligation in anaesthetised rats

\begin{tabular}{|c|c|c|c|c|c|c|c|c|}
\hline \multirow[t]{2}{*}{ Group } & \multirow{2}{*}{$\begin{array}{l}\text { Dose } \\
(\mathrm{mg} / \mathrm{kg})\end{array}$} & \multirow[t]{2}{*}{$N$} & \multirow{2}{*}{$\begin{array}{l}\text { Survived } \\
(\%)\end{array}$} & \multicolumn{5}{|c|}{ Incidence of arrhythmias (\%) } \\
\hline & & & & None & RevVF & IrrevVF & VT & Other \\
\hline Control & & 22 & 27 & 0 & 9 & 73 & 100 & 100 \\
\hline \multirow[t]{2}{*}{ Glibenclamide } & 0.01 & 13 & 31 & 0 & 8 & 69 & 100 & $62^{\mathrm{a}}$ \\
\hline & 5.0 & 16 & $81^{\mathrm{a}}$ & 0 & $75^{\mathrm{a}}$ & $19^{\mathrm{a}}$ & 100 & 94 \\
\hline \multirow[t]{3}{*}{ Glimepiride } & 0.0001 & 8 & 38 & 0 & 37 & 63 & 100 & 100 \\
\hline & 0.001 & 22 & $64^{\mathrm{a}}$ & 5 & 32 & $36^{\mathrm{a}}$ & 91 & 96 \\
\hline & 5.0 & 18 & $67^{\mathrm{a}}$ & 0 & $50^{\mathrm{a}}$ & $33^{\mathrm{a}}$ & 100 & 72 \\
\hline
\end{tabular}

$N=$ Total number of animals at the beginning of reperfusion; None $=$ no arrhythmia developed; RevVF $=$ reversible ventricular fibrillation; IrrevVF $=$ irreversible ventricular fibrillation; VT = ventricular tachycardia; Other = ventricular extrasystoles, bigeminy, and salvo.

${ }^{\mathrm{a}} P<0.05$ compared to the corresponding control value.

ular fibrillation occurred in $73 \%$ of the control animals and there was no animal surviving without developing arrhythmias during reperfusion (Table 3). Only 2 of 18 animals recovered spontaneously from ventricular fibrillation in the control group. Both glibenclamide and glimepiride increased the survival rate during reperfusion after $6 \mathrm{~min}$ myocardial ischaemia in anaesthetised rats and this protective effect of glimepiride was significant after using smaller doses $(0.01$ and $0.001 \mathrm{mg} / \mathrm{kg}$, Table 3$)$.

Both glibenclamide and glimepiride decreased significantly the incidence of irreversible ventricular fibrillation occurring during reperfusion after 6 min coronary occlusion. However, the dose required to produce this effect was much smaller with glimepiride (i.e., $0.001-0.1 \mathrm{mg} / \mathrm{kg}$ ) than with glibenclamide $(5 \mathrm{mg} / \mathrm{kg}$, Table 3$)$. The incidence of ventricular tachycardia and other types of arrhythmias did not show a dose related change after the pretreatments.

The length of arrhythmic attacks was also measured in the animals surviving reperfusion. As compared to the control animals, neither glibenclamide nor glimepiride treatment decreased the mean length of arrhythmic attacks or the total period that was characterized by arrhythmias during reperfusion.

\section{Discussion}

Transient coronary artery ligation followed by reperfusion in the anaesthetised rat is a widely used and accepted method to investigate the efficacy of antiarrhythmic treatments. In the present investigations, we applied $6 \mathrm{~min}$ occlusion of the left main coronary artery that was not long enough for a significant amount of ischaemia-induced arrhythmias to develop, however, it was purposely chosen to prime the heart to develop severe arrhythmias consistently 10-30 s following the start of reperfusion.

The present results demonstrate that pretreatment with two sulphonylureas, glibenclamide or glimepiride, signifi- cantly decreased the incidence of irreversible ventricular fibrillation during reperfusion following a brief period of myocardial ischaemia in anaesthetised rats. Moreover, this cardioprotective action of glimepiride occurred in smaller doses than that producing a blood glucose lowering effect.

It has been suggested that sulphonylureas may inhibit the opening of $\mathrm{K}_{\text {АTP }}$ channels during myocardial ischaemia, thereby preventing the loss of intracellular $\mathrm{K}^{+}$ from jeopardised cells and the non-uniform shortening of the action potential during myocardial ischaemia (MacKenzie et al., 1993; Tweedie et al., 1993). Such an effect by $\mathrm{K}_{\text {ATP }}$ inhibitors, like glibenclamide or glimepiride, could decrease the development of electric inhomogeneity between the ischaemic and non-ischaemic myocardium and might suppress the substrate for re-entrant pathways, resulting in antiarrhythmic, antifibrillatory action. Such an idea is supported by many investigators using glibenclamide in various in vitro (Pogatsa et al., 1988; Wolleben et al., 1989; Kantor et al., 1990; Tosaki et al., 1993; D'Alonzo et al., 1994), as well as under in vivo experimental conditions (Bekheit et al., 1990; Billman et al., 1993; Kondo et al., 1996).

Very few data are available on the possible antiarrhythmic effect of glimepiride. Vegh and Papp (1996) have found that only glimepiride but not glibenclamide attenuated the number of episodes and the incidence of ventricular tachycardia during ischaemia after coronary artery ligation in anaesthetised dogs. Our present investigations corroborate these findings and support that, in a wide dose range, glimepiride provides a more potent antiarrhythmic effect than glibenclamide.

The reason for the observed difference between glibenclamide and glimepiride, and the divergence of the blood glucose lowering potency and the 'antiarrhythmic' activity is not known. However, there are some data that also describe differences in the various actions of these two compounds. Ozaki et al. (1992) found that glimepiride inhibited the cyclooxygenase pathway of isolated human platelets, while the activities of 12-lipoxygenase and phos- 
pholipase $\mathrm{A}_{2}$ were not influenced. On the other hand, glibenclamide inhibited both the cyclooxygenase and 12lipoxygenase enzymes and also the phospholipase $\mathrm{A}_{2}$. Muller et al. (1994) described that glimepiride, in spite of its higher blood glucose lowering potency in diabetic patients than that of glibenclamide, had a 2.5-3-fold lower affinity to membranes isolated from rat pancreatic $\beta$-cells. Bijlstra et al. (1996) found that forearm vasodilator response to the administration of the specific $\mathrm{K}_{\mathrm{ATP}}$ channel opener diazoxide was significantly inhibited by therapeutic concentrations of glibenclamide, while glimepiride was devoid of such effect. Perhaps, differences in the effects on membrane currents or in direct metabolic effects, not related to the increased secretion of insulin, e.g., increased glucogenolysis, decreased fatty acid metabolism (reviewed by Schotborgh and Wilde, 1997), could be related to the more pronounced 'antifibrillatory' action of glimepiride than that of glibenclamide. The observed difference in the blood glucose lowering and the 'antiarrhythmic' activity of sulphonylurea compounds may also correlate with the multiplicity of sulphonylurea receptors that regulate the opening of ATP-dependent $\mathrm{K}^{+}$channels. The contribution of these possibilities to the difference between glibenclamide and glimepiride revealed in the present study needs further investigations.

The observed differences between the two sulphonylurea compounds may suggest the possibility to develop 'cardioselective' compounds that inhibit $\mathrm{K}_{\mathrm{ATP}}$-channels without decreasing blood glucose level. This conclusion is supported by recent findings that a novel 'cardioselective' $\mathrm{K}_{\text {ATP }}$ antagonist, HMR 1883 reduced the incidence of ventricular fibrillation, induced by 2 min coronary artery occlusion during submaximal exercise test in mongrel dogs with healed myocardial infarction (Billman et al., 1998). Such compounds may be possible candidates for the drug treatment of cardiac arrhythmias with a selective action during myocardial ischaemia.

\section{Acknowledgements}

We thank Mrs. Zsuzsa Ábrahám and Mrs. Anikó Deákné-Tóth for their skillful technical assistance. This work was supported by grants from the Hungarian National Research Fund (OTKA T22300) and the Ministry of Welfare (ETT T06127 and T06521).

\section{References}

Aguilar-Bryan, L., Clement, J.P., Gonzalez, G., Kunjilwar, K., Babenko, A., Bryan, J., 1998. Toward understanding the assembly and structure of $\mathrm{K}_{\text {ATP }}$ channels. Physiol. Rev. 78, 227-245.

Baczkó, I., Leprán, I., Papp, J.Gy., 1997a. K increase survival rate during coronary occlusion-reperfusion in anaesthetized rats. Eur. J. Pharmacol. 324, 77-83.

Baczkó, I., Leprán, I., Papp, J.Gy., 1997b. Influence of anesthetics on the incidence of reperfusion-induced arrhythmias and sudden death in rats. J. Cardiovasc. Pharmacol. 29, 196-201.

Ballagi-Pordany, G., Koszeghy, A., Koltai, M.Z., Aranyi, Z., Pogatsa, G., 1990. Divergent cardiac effects of the first and second generation hypoglycemic sulfonylurea compounds. Diabetes Res. Clin. Pract. 8, 109-114.

Bekheit, S.S., Restivo, M., Boutjdir, M., Henkin, R., Gooyandeh, K., Assadi, M., Khatib, S., Gough, W.B., El-Sherif, N., 1990. Effects of glyburide on ischemia-induced changes in extracellular $\mathrm{K}^{+}$and local myocardial activation: a potential new approach to the management of ischemia-induced malignant ventricular arrhythmias. Am. Heart J. $119,1025-1033$

Bernauer, W., 1997. Concerning the effect of the $\mathrm{K}^{+}$channel blocking agent glibenclamide on ischaemic and reperfusion arrhythmias. Eur. J. Pharmacol. 326, 147-156.

Bijlstra, P.J., Lutterman, J.A., Russel, F.G.M., Thien, T., Smits, P., 1996. Interaction of sulphonylurea derivatives with vascular ATP-sensitive potassium channels in humans. Diabetologia 39, 1083-1090.

Billman, G.E., Avendano, C.E., Halliwill, J.R., Burroughs, J.M., 1993. The effects of ATP-dependent potassium channel antagonist, glyburide, on coronary flow and susceptibility to ventricular fibrillation in unanesthetized dogs. J. Cardiovasc. Pharmacol. 21, 197-207.

Billman, G.E., Englert, H.C., Scholkens, B.A., 1998. HMR 1883, a novel cardioselective inhibitor of the ATP-sensitive potassium channel: Part II. Effects on susceptibility to ventricular fibrillation induced by myocardial ischemia in conscious dogs. J. Pharmacol. Exp. Ther. 286, 1465-1473.

Bril, A., Laville, M.P., Gout, B., 1992. Effects of glibenclamide on ventricular arrhythmias and cardiac function in ischaemia and reperfusion in isolated rat heart. Cardiovasc. Res. 26, 1069-1076.

Chi, L., Uprichard, A.C.G., Lucchesi, B.R., 1989. Failure of glibenclamide to protect against ischemic ventricular fibrillation in a canine model of myocardial infarction. J. Mol. Cell. Cardiol. 21, S89.

Cole, W.C., Mcpherson, C.D., Sontag, D., 1991. ATP-regulated K ${ }^{+}$ channels protect the myocardium against ischemia/reperfusion damage. Circ. Res. 69, 571-581.

D’Alonzo, A.J., Darbenzio, R.B., Hess, T.A., Sewter, J.C., Sleph, P.G., Grover, G.J., 1994. Effect of potassium on the action of the $\mathrm{K}_{\text {ATP }}$ modulators cromakalim, pinacidil, or glibenclamide on arrhythmias in isolated perfused rat heart subjected to regional ischaemia. Cardiovasc. Res. 28, 881-887.

Escande, D., Cavero, I., 1992. $\mathrm{K}^{+}$channel openers and natural cardioprotection. Trends Pharmacol. Sci. 13, 269-272.

Geisen, K., 1988. Special pharmacology of the new sulfonylurea glimepiride. Arzneim.-Forsch. (Drug Res.) 38, 1120-1130.

Geisen, K., Vegh, A., Krause, E., Papp, J.Gy., 1996. Cardiovascular effects of conventional sulfonylureas and glimepiride. Horm. Metab. Res. 28, 496-507.

Grover, G.J., 1994. Protective effects of ATP sensitive potassium channel openers in models of myocardial ischaemia. Cardiovasc. Res. 28, 778-782.

Kantor, P.F., Coetzee, W.A., Carmeliet, E.E., Dennis, S.C., Opie, L.H., 1990. Reduction of ischemic $\mathrm{K}^{+}$loss and arrhythmias in rat hearts. Effect of glibenclamide, a sulphonylurea. Circ. Res. 66, 478-485.

Kondo, T., Kubota, I., Tachibana, H., Yamaki, M., Tomoike, H., 1996. Glibenclamide attenuates peaked $\mathrm{T}$ wave in early phase of myocardial ischemia. Cardiovasc. Res. 31, 683-687.

Langtry, H.D., Balfour, J.A., 1998. Glimepiride: a review of its use in the management of type 2 diabetes mellitus. Drugs 55, 563-584.

Leprán, I., Koltai, M., Siegmund, W., Szekeres, L., 1983. Coronary artery ligation, early arrhythmias, and determination of the ischemic area in conscious rats. J. Pharmacol. Methods 9, 219-230.

Leprán, I., Baczkó, I., Varró, A., Papp, J.Gy., 1996. ATP-sensitive potassium channel modulators: both pinacidil and glibenclamide produce antiarrhythmic activity during acute myocardial infarction in conscious rats. J. Pharmacol. Exp. Ther. 277, 1215-1220.

MacKenzie, I., Saville, V.L., Waterfall, J.F., 1993. Differential class III 
and glibenclamide effects on action potential duration in guinea-pig papillary muscle during normoxia and hypoxia/ischaemia. Br. J. Pharmacol. 110, 531-538.

Muller, G., Hartz, D., Punter, J., Okonomopulos, R., Kramer, W., 1994. Differential interaction of glimepiride and glibenclamide with the beta-cell sulfonylurea receptor: I. Binding characteristics. Biochim. Biophys. Acta 1191, 267-277.

Noma, A., 1983. ATP-regulated $\mathrm{K}^{+}$channels in cardiac muscle. Nature 305, 147-149.

Ozaki, Y., Yatomi, Y., Kume, S., 1992. Effects of oral hypoglycaemic agents on platelet functions. Biochem. Pharmacol. 44, 687-691.

Pogatsa, G., Koltai, M.Z., Balkanyi, I., Devai, I., Kiss, V., Koszeghy, A., 1988. The effect of various hypoglycaemic sulphonylureas on the cardiotoxicity of glycosides and arrhythmogenic activity due to myocardial ischaemia. Acta Physiol. Hung. 71, 243-250.

Rees, S.A., Curtis, M.J., 1995. Pharmacological analysis in rat of the role of the ATP-sensitive potassium channel as a potential target for antifibrillatory intervention in acute myocardial ischaemia. J. Cardiovasc. Pharmacol. 26, 280-288.

Schotborgh, C.E., Wilde, A.A.M., 1997. Sulfonylurea derivatives in cardiovascular research and in cardiovascular patients. Cardiovasc. Res. 34, 73-80.
Tosaki, A., Szerdahelyi, P., Engelman, R.M., Das, D.K., 1993. Potassium channel openers and blockers: do they possess proarrhythmic or antiarrhythmic activity in ischemic and reperfused rat hearts?. J. Pharmacol. Exp. Ther. 267, 1355-1362.

Tweedie, D., Henderson, C., Kane, K., 1993. Glibenclamide, but not class III drugs, prevents ischaemic shortening of the refractory period in guinea-pig hearts. Eur. J. Pharmacol. 240, 251-257.

Vegh, A., Papp, J.Gy., 1996. Haemodynamic and other effects of sulphonylurea drugs on the heart. Diabetes Res. Clin. Pract. 31, S43-S53, Suppl.

Walker, M.J.A., Curtis, M.J., Hearse, D.J., Campbell, R.W.F., Janse, M.J., Yellon, D.M., Cobbe, S.M., Coker, S.J., Harness, J.B., Harron, D.W.G., Higgins, A.J., Julian, D.G., Lab, M.J., Manning, A.S., Northover, B.J., Parratt, J.R., Riemersma, R.A., Riva, E., Russell, D.C., Sheridan, D.J., Winslow, E., Woodward, B., 1988. The Lambeth Conventions: guidelines for the study of arrhythmias in ischemia, infarction, and reperfusion. Cardiovasc. Res. 22, 447-455.

Wallenstein, S., Zucker, C.L., Fleiss, J.L., 1980. Some statistical methods useful in circulation research. Circ. Res. 47, 1-9.

Wolleben, C.D., Sanquinetti, M.C., Siegl, P.K.S., 1989. Influence of ATP-sensitive potassium modulators on ischemia-induced fibrillation isolated rat hearts. J. Mol. Cell. Cardiol. 21, 783-788. 